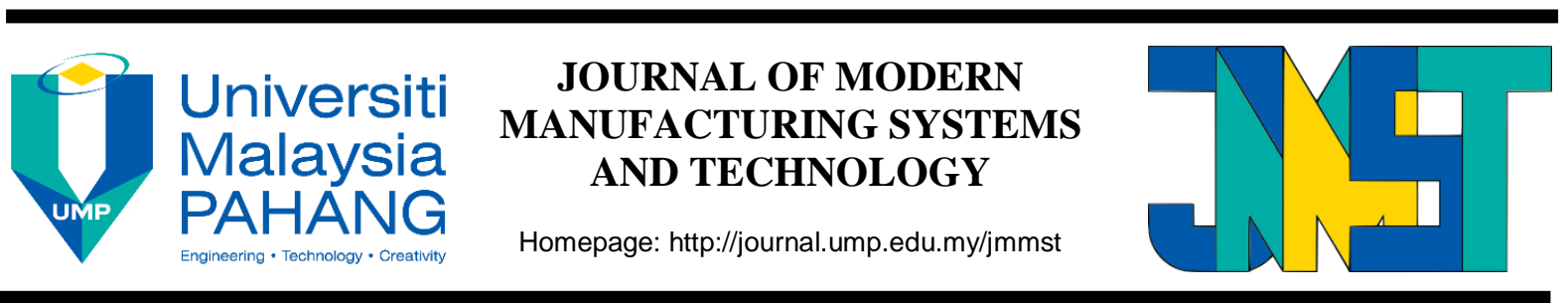

\title{
APPLICATION OF MAHALANOBIS-TAGUCHI SYSTEM IN PALM OIL PLANTATION
}

\author{
I.I. Azmi ${ }^{1+}$, S.N.A.M. Zaini ${ }^{1+}$ and M.Y. Abu ${ }^{1 *}$
}

\begin{tabular}{|c|c|}
\hline${ }^{*}$ Correspondence & ABSTRACT \\
\hline $\begin{array}{l}\text { myazid@ump.edu.my } \\
\text { +This author contributes } \\
\text { equally to this work } \\
{ }^{1} \text { Faculty of Manufacturing } \\
\text { and Mechatronic Technology } \\
\text { Engineering, Universiti } \\
\text { Malaysia Pahang, 26600, } \\
\text { Pekan, Pahang, Malaysia }\end{array}$ & $\begin{array}{l}\text { This work deals with the palm oil plantation which is not utilizing the available data to be } \\
\text { used as reference to measure the degree of abnormal observation. There are no assessment } \\
\text { tools to quantify the degree of seriousness of abnormal observation. When a palm oil } \\
\text { plantation is ignoring the optimization of the factors contributing to the problem, they might } \\
\text { produce lots of waste. The objective of this work is to measure the degree of abnormality } \\
\text { using Mahalanobis Taguchi System (MTS) and to diagnose the parameters that influence }\end{array}$ \\
\hline $\begin{array}{l}\text { Articles Info: } \\
\text { Received } 3 \text { August } 2019 \\
\text { Received in revised form } \\
10 \text { September } 2019 \\
\text { Accepted } 29 \text { September } \\
\mathbf{2 0 1 9} \\
\text { Available Online } 30 \\
\text { September } 2019\end{array}$ & $\begin{array}{l}\text { the system. MTS is a method used for identifying or to see the pattern in decision making. } \\
\text { The main principle MTS is to choose a group of variables and achieve optimization of the } \\
\text { factors that contributes to the problem by embodying with Mahalanobis Distance. From the } \\
\text { results, the degree of abnormality was successfully measured using the MTS method. There } \\
\text { are } 5 \text { sample blocks that belong in the abnormality group; PR16 B3, PR17 C5, PR15 A5, } \\
\text { PR16 B5 and PR17 C4. The acquired result indicates that interrow weeding is the parameters }\end{array}$ \\
\hline $\begin{array}{l}\text { Keywords: } \\
\text { Palm oil plantation; } \\
\text { Mahalanobis-Taguchi } \\
\text { System; Mahalanobis } \\
\text { distance. }\end{array}$ & $\begin{array}{l}\text { that most influence the process flow in plantation. This variable contributes to } 25 \% \text { of the } \\
\text { abnormal data. It can be concluded here is this parameter need to be diagnosed by } \\
\text { increasing the dosage of interrow weeding so that the harvesting output performance can } \\
\text { be improve. }\end{array}$ \\
\hline
\end{tabular}

\section{INTRODUCTION}

In 1959, the newly independent Malayan government set-up the Federal Land Development Authority (FELDA), whose aim to settle landless poor on oil palm smallholdings throughout the country. The result was to open up vas areas of the previously untouched hinterland in the Peninsula and later east Malaysia. FELDA has come to be regarded as one of the major success stories among $\mathrm{s}$ tropical rural resettlement schemes. Each smallholder family was provided with a basic house and 10-15 acres of oil palm, planted and ready for harvesting. Each settlement scheme was run on estate lines, and the settles worked on the scheme, or in the mill, a deduction was made, fluctuating with the price of palm oil. The enabled the outlay on each settler's house and 10-15 acres of palm to be fully repaid, within 10 years. Indeed, it proved so successful that in many cases settles ware able to send their children for professional education, to become doctors, lawyers, and accountants. Palm oil has been one of the contributors to the growth of Malaysian economy for the last hundred years. Malaysia once used to be the largest palm oil exporter to the whole world before Indonesia managed to take over the no one spot the past few years. Nonetheless palm oil industry of Malaysia still continues to contribute to the economy strongly by providing $4.2 \%$ to its gross domestic product. To promote and develop the palm oil industry in Malaysia, MPOB is the government agency that is responsible for this task. Malaysia produces roughly 90 million tons of biomass product, including palm oil mill and oil palm trunks. In concerns of environmental impact, the 
government give assurances in 2010 that palm oil plantation expansion will be limit for at least half of Malaysia land as the forest cover. The development by FELDA of what eventually totaled some 850,000-ha including 500,000 ha of smallholder schemes had a massive impact on the country and the palm oil industry. State government also become involved, developing their own state land into major schemes of 5,000 - 10,000 ha, partly g=finances by Federal government grants, and implemented in the early years by the Agency houses who had expertise to clear and develop large areas of logged over secondary forest. Between 1975-1990, annual crude palm oil production rose from just q million to over 6 million tons. Table 1 shows the palm oil plantation accounted in the Malaysia as in 2016. The total area used in $57,400 \mathrm{~km}^{2}$. Some of the largest plantation companies in the world is based in Malaysia. Based on the plantation area globally, Malaysia's Sime Darby is the largest palm oil company. The company was created by Malaysia government in December 2006 while Felda Global Venture Holdings (FGV) fall to the second world's largest palm oil plantation. Felda_controlling over 850,000 ha of land in the country that is include approximately 500,000 ha for smallholders.

Table 1 Palm Oil Plantation Area in Malaysia by State [1].

\begin{tabular}{cccc}
\hline State & $\begin{array}{c}\text { Plantation area } \\
\text { (hectares) }\end{array}$ & $\begin{array}{c}\text { Percentage of total } \\
\text { plantation area }\end{array}$ & $\begin{array}{c}\text { Percentage of state } \\
\text { area }\end{array}$ \\
\hline Sabah & $1,551,714$ & $27.0 \%$ & $21.1 \%$ \\
\hline Sarawak & $1,506,769$ & $26.3 \%$ & $12.1 \%$ \\
\hline Johor & 745,630 & $13.0 \%$ & $38.8 \%$ \\
\hline Pahang & 732,052 & $12.8 \%$ & $20.3 \%$ \\
\hline Perak & 397,908 & $6.9 \%$ & $18.9 \%$ \\
\hline Negeri Sembilan & 178,958 & $3.1 \%$ & $26.8 \%$ \\
\hline Terengganu & 171,943 & $3.0 \%$ & $13.2 \%$ \\
\hline Kelantan & 155,458 & $2.7 \%$ & $10.3 \%$ \\
\hline Selangor & 138,831 & $2.4 \%$ & $33.7 \%$ \\
\hline Kedah & 87,786 & $1.5 \%$ & $13.5 \%$ \\
\hline Melaka & 56,149 & $1.0 \%$ & $9.2 \%$ \\
\hline Penang & 14,135 & 0.2 & $0.8 \%$ \\
\hline Perlis & 652 & $0.0 \%$ &
\end{tabular}

Mahalanobis-Taguchi system is a method proposed by Genichi Taguchi. MTS is an analytical method used for the diagnosis and/or pattern recognition of for quantitative decision making [2]. The basic principle of MTS is to select a characteristic variable and to achieve the goal of dimensionality reduction and system optimization by integrating the orthogonal experimental design concept with MD [3]. Methods proposed for behavior patterns diagnosis and prognosis is MTS which is relatively the new method for data collection [4]. The main purpose of MTS is to develop and optimize a diagnostic system with a measurement scale to classify multivariate data [5]. The data are divided into "healthy" and "unhealthy" observations. Mahalanobis distance is used to measure the abnormality on the observations. The advantage of MTS is the method is very general and can be used for many types of tasks in the organization of testing and development of software systems [6]. The method can help in decision making and to avoid unscheduled maintenance and the reduction of financial losses [7]. Moreover, MTS can cover interactions among many factors by using orthogonal array analysis [8]. In addition, MTS takes into account the correlation between variables [9]. The disadvantage of MTS lacks a method for determining an efficient threshold for the binary classification [10]. Other than that, MTS has problem to solve screening variable [11]. Based on the pie chart in Figure 1, there are many different application areas that applied MTS method in their research. Among them, manufacturing field is the most work of MTS method that had been done. Meanwhile software and agriculture got the lowest percent which is 1 for each application area. This prove that there are less references for agriculture field in MTS method. 


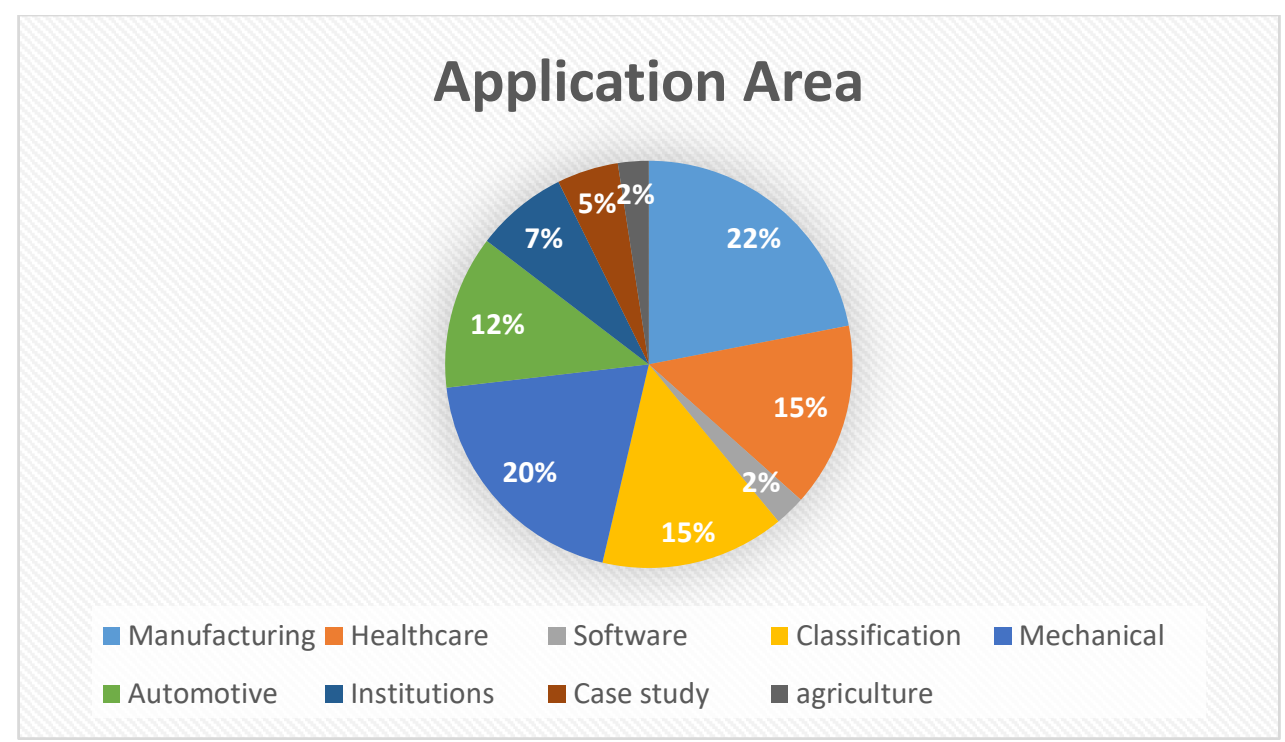

Figure 1 Application Area.

\section{METHODOLOGY}

The methodology was divided into four main stages. Phase 1 basically made up of the literature review to prove the research gap in MTS. To ensure the work is in the right boundary, the objectives are set within the scope. Suitable tools to be used can be identify by general analysis. Phase 2 made up of endorsing the plantation company, plantation component selection, parameter selection and data collection as shown in Figure 2. Phase 3 is basically about data analysis, which using the MTS method. The method is classified to construction of Mahalanobis space, Mahalanobis space validation, identification of the most useful set of variables and diagnostic and prediction of future observations. Finally, phase 4 is to express the overall conclusion by analyzed and conclude the findings. The selection of the component was done in the Simpai Division 1 Estate where there is a total of 15 block of plantation areas. The areas were categorized into palm trees that were planted in year of 2015, 2016 and 2017.

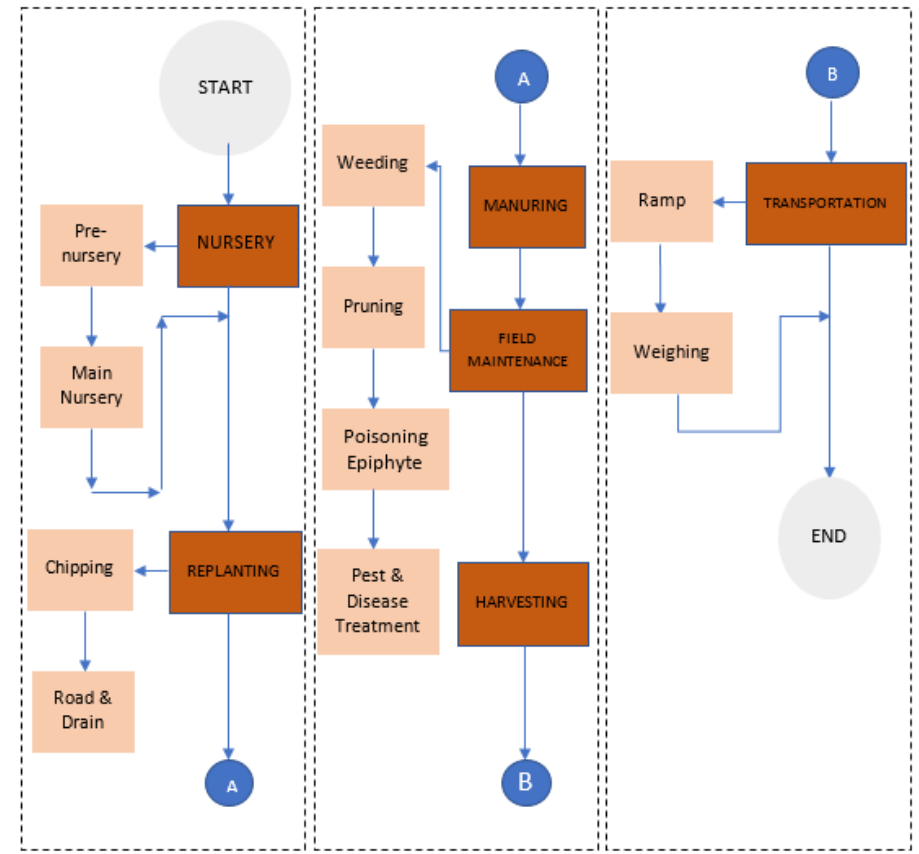

Figure 2 Process flow.

MTS was bringing into effective action to carry out the analysis of the data collected. Analysis of the data by MTS was complete in four phases; 
i. Construction of Mahalanobis space

ii. Mahalanobis space validation

iii. Identification of the most useful set of variables

iv. Diagnostic and prediction of future observations

\section{RESULT AND DISCUSSION}

The study was conducted by collecting the data of 15 blocks of palm oil plantations in the Simpai Division 1 Estate. The analyze were carried out in Kanri Distance Calculator in order to build up the Mahalanobis space. The purpose of Kanri approach is to provide a management system based on several variables that are related. Based on the information about these attributes a multivariate measurement scale is developed to measure the distances from a target or reference group defined as successful. Table 2 shows the data that were collected at the plantation. The variables that are taken into account to measure the Mahalanobis distance is:
i. $\quad$ Area (Acre)
ii. Number of palm trees
iii. Interow weeding (pump)
iv. Circle weeding (pump)
v. Orycytes (pump)
vi. As Kali DAP (MT)
vii. $\quad$ CIRP (MT)

Table 2 Tabulate data of replanting process.

\begin{tabular}{|c|c|c|c|c|c|c|c|c|}
\hline Block & $\begin{array}{c}\text { AREA } \\
\text { (ACRE) }\end{array}$ & $\begin{array}{l}\text { PALM } \\
\text { TREE }\end{array}$ & $\begin{array}{c}\text { INTEROW } \\
\text { WEEDING } \\
\text { (PUMP) }\end{array}$ & $\begin{array}{c}\text { CIRCLE } \\
\text { WEEDING } \\
\text { (PUMP) }\end{array}$ & $\begin{array}{c}\text { Orycytes } \\
\text { (PUMP) }\end{array}$ & $\begin{array}{c}\text { AS KALI } \\
\text { DAP } \\
\text { (MT) }\end{array}$ & $\begin{array}{l}\text { CIRP } \\
\text { (MT) }\end{array}$ & $\begin{array}{c}\text { HARVEST } \\
\text { (FFB/MONTH) }\end{array}$ \\
\hline PR15 A1 & 173.7 & 9553 & 87 & 58 & 72 & 47.6 & 14.85 & 138.96 \\
\hline PR15 A2 & 110.2 & 6061 & 55 & 37 & 45 & 33.4 & 10.45 & 88.16 \\
\hline PR15 A3 & 117.9 & 6485 & 59 & 39 & 49 & 28 & 8.75 & 94.32 \\
\hline PR15 A4 & 124.3 & 6837 & 62 & 41 & 51 & 35.8 & 11.2 & 99.44 \\
\hline PR15 A5 & 67.6 & 3718 & 34 & 23 & 28 & 15.4 & 4.65 & 53.72 \\
\hline PR16 B1 & 138.4 & 7612 & 69 & 46 & 57 & 29.8 & 8.95 & 110.72 \\
\hline PR16 B2 & 137.9 & 7585 & 69 & 46 & 57 & 29.8 & 8.95 & 110.32 \\
\hline PR16 B3 & 79.1 & 4351 & 40 & 26 & 33 & 16.4 & 4.95 & 63.28 \\
\hline PR16 B4 & 138.9 & 7640 & 69 & 46 & 57 & 30 & 8.95 & 111.12 \\
\hline PR16 B5 & 61.5 & 3383 & 31 & 21 & 25 & 15 & 4.45 & 49.2 \\
\hline PR17 C1 & 170 & 9350 & 85 & 57 & 70 & 24.7 & 9.5 & 136 \\
\hline PR17 C2 & 109.7 & 6034 & 55 & 37 & 45 & 17.4 & 6.7 & 87.76 \\
\hline PR17 C3 & 183.8 & 10109 & 92 & 61 & 76 & 34.2 & 11.05 & 147.04 \\
\hline PR17 C4 & 70.7 & 3889 & 35 & 24 & 29 & 15.8 & 4.7 & 58.53 \\
\hline PR17 C5 & 84.6 & 4653 & 42 & 28 & 35 & 16.9 & 5.2 & 67.82 \\
\hline
\end{tabular}

As shown in Figure 3, this off-target participant histogram displays the total count of participant belonging to a specific distance bin range. The figure above shows 5 sample, two falling within the distance range of 9-7, the other 3 in range of 7-5. The sample blocks that falls within the distance range of 9-7 is PR16 B3 and PR17 C5 while the sample blocks fall within distance range of 7-5 is PR15 A5, PR16 B5 and PR17 C4. 


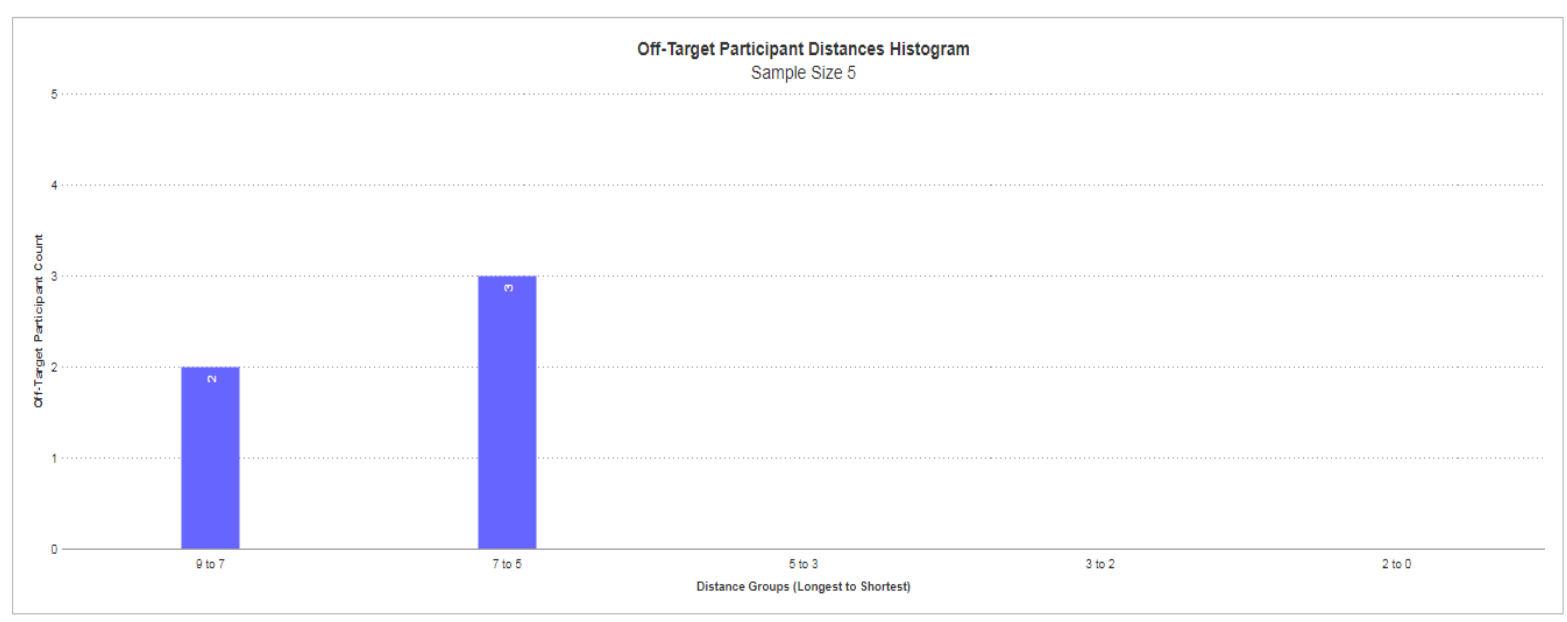

Figure 3 Off-target distance histogram.

From the Figure 4, the result shown that there are root cause contributions for two off-target sample blocks of PR16 B3 and PR17 C5 that falls within distance group of 9 to 7. From PR16 B3, all 7 variables were affecting the Mahalanobis distance of sample PR16 B3 which is 9. Variable of Palm Trees contribute to value of 1.6 to the MD of the sample block which is the highest while the variables of orycytes pump contributes the lowest value of MD to the block PR16 B3 that is 1 only. It can be said here that the total number of palm trees in the block is too high compare to the total dosage of orycytes pesticides. Its causes the increases in number of orycytes pest and would inflict serious damage on oil palm trees.

On the other hand, only 5 variables were affecting the Mahalanobis distance of sample block PR17 C5. Interow weeding is the highest variable contributor to the block with value of 3.1 whereas the lowest variable contributor to the sample block is As Kali DAP manuring which is 0.8 only. There is not enough of interrow weeding operation at the PR17 C5 block that causes the high Mahalanobis distance. Weeds are harmful and will interfere with the harvesting of fresh fruit bunch since the oil palm trees will need to compete with other plants in nutrient uptake.

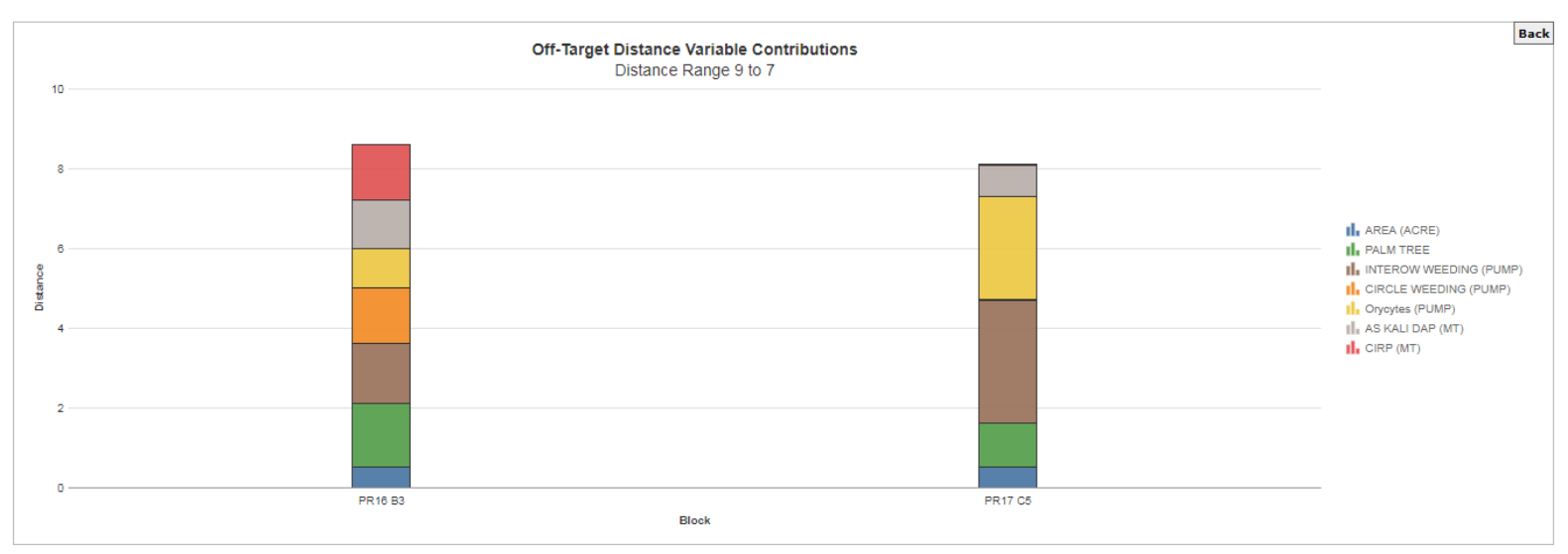

Figure 4 Off-target distance variable contributions for distance range 9 to 7.

Furthermore, Figure 5 shows the root cause contributions for three off-target sample block that is PR16 A5, PR16 B5 and PR17 C4. Those unhealthy data fall within the distance range of 7 to 5. First, for the sample block PR16 A5, there are six variables that directly affecting the Mahalanobis distance to become 7. Among those, the highest contributors for the distance range is area of the block with value of 2.1 while CIRP manuring is the lowest contributors with the value of 0.1 . From the result provided, undoubtedly the area of the block is large compared to the value of other five parameters cause them to be less significant and decreases the harvest production.

Second, for the sample block PR16 B5, the value of Mahalanobis distance is 5 with only five variables that influence the sample block. The highest variable contributor is also the area of the block with value of 2. The lowest variable contributor is CIRP manuring with value of 0.1. Similarly, as block PR16 A5, the large area of the plantation block leads to the large Mahalanobis distance. The dosage of interrow 
weeding, circle weeding and CIRP manuring proved to be wholly inadequate to produce a harvest above the target output.

Lastly, for the fifth sample block, PR17 C4 has the Mahalanobis distance of 5. On the contrary with the two sample block before, the highest variable contributor is the interrow weeding with the value of 2.5 while the lowest variable contributor is the number of palm trees and CIRP manuring with the value of 0.1 . The result at block PR17 C4 shows that the dosage of interrow weeding is less compared to the number of palm trees. Due to this matter, the weeds will grow without control and palm trees will compete with the weeds for the resources such as nutrients and water.

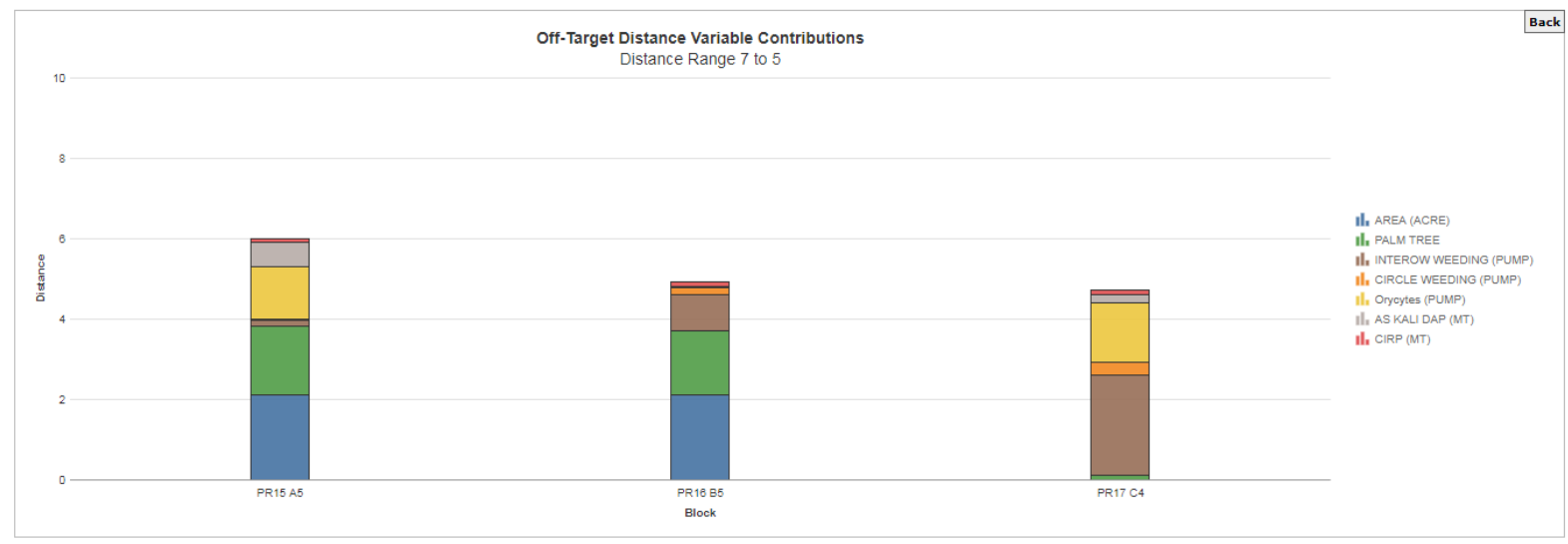

Figure 5 Off-target distance variable contributions for distance range 7 to 5 .

Table 3 and Table 4 will make clear on the values of Mahalanobis distance that influence to the off-target data in the palm oil plantation.

Table 3 Off-Target variable Mahalanobis Distance.

\begin{tabular}{cccccccc}
\hline Block & Acre & $\begin{array}{c}\text { Palm } \\
\text { Tree }\end{array}$ & $\begin{array}{c}\text { Interow } \\
\text { weeding }\end{array}$ & $\begin{array}{c}\text { Circle } \\
\text { weeding }\end{array}$ & $\begin{array}{c}\text { Orycytes } \\
\text { Spraying }\end{array}$ & $\begin{array}{c}\text { As Kali } \\
\text { DAP }\end{array}$ & CIRP \\
\hline PR16 B3 & 6 & 6 & 19 & 17 & 13 & 15 & 17 \\
\hline PR17 C5 & 6 & 6 & 14 & 1 & 32 & 10 & 1 \\
\hline PR15 A5 & 35 & 35 & 28 & 1 & 22 & 11 & 2 \\
\hline PR16 B5 & 43 & 34 & 34 & 4 & 1 & 0 & 3 \\
\hline PR17 C4 & 0 & 2 & 2 & 7 & 33 & 5 & 2 \\
\hline
\end{tabular}

Table 4 Off-Target variable Mahalanobis Distance in Percent.

\begin{tabular}{cccccccc}
\hline Block & Acre & $\begin{array}{c}\text { Palm } \\
\text { Tree }\end{array}$ & $\begin{array}{c}\text { Interow } \\
\text { weeding }\end{array}$ & $\begin{array}{c}\text { Circle } \\
\text { weeding }\end{array}$ & $\begin{array}{c}\text { Orycytes } \\
\text { Spraying }\end{array}$ & $\begin{array}{c}\text { As Kali } \\
\text { DAP }\end{array}$ & CIRP \\
\hline PR16 B3 & 6 & 6 & 19 & 17 & 13 & 15 & 17 \\
\hline PR17 C5 & 6 & 6 & 14 & 1 & 32 & 10 & 1 \\
\hline PR15 A5 & 35 & 35 & 28 & 1 & 22 & 11 & 2 \\
\hline PR16 B5 & 43 & 34 & 34 & 4 & 1 & 0 & 3 \\
\hline PR17 C4 & 0 & 2 & 2 & 7 & 33 & 5 & 2 \\
\hline
\end{tabular}

The pie chart above shows each of variable contributions to the MD of off-target sample. Its shows that variable of interrow weeding is the most dominant variables in the off-target distance contribution which is $25 \%$. Undoubtedly, this variable is the most affecting the data output of harvesting in the Simpai division 1 estate. On the contrary, manuring using CIRP is the lowest contribution to the Mahalanobis distance which is $5 \%$ only. The percentage of contribution variables of circle weeding, As Kali DAP manuring and CIRP manuring are grouped closely together with 6\%, 8\% and 5\%. Meanwhile, the percentage contribution variables of area of block, number of palm tree and orycytes pump are grouped closely together with $17 \%, 19 \%$ and $20 \%$. To sum up, interrow weeding is the variable that need an alteration. This variable plays a huge role in the unhealthy group of plantation block of palm oil. The variables of area of block, number of palm trees and orycytes pump also may need to give a bit alteration as their contribution to the Mahalanobis distance is not far compared to variable of interrow weeding. 


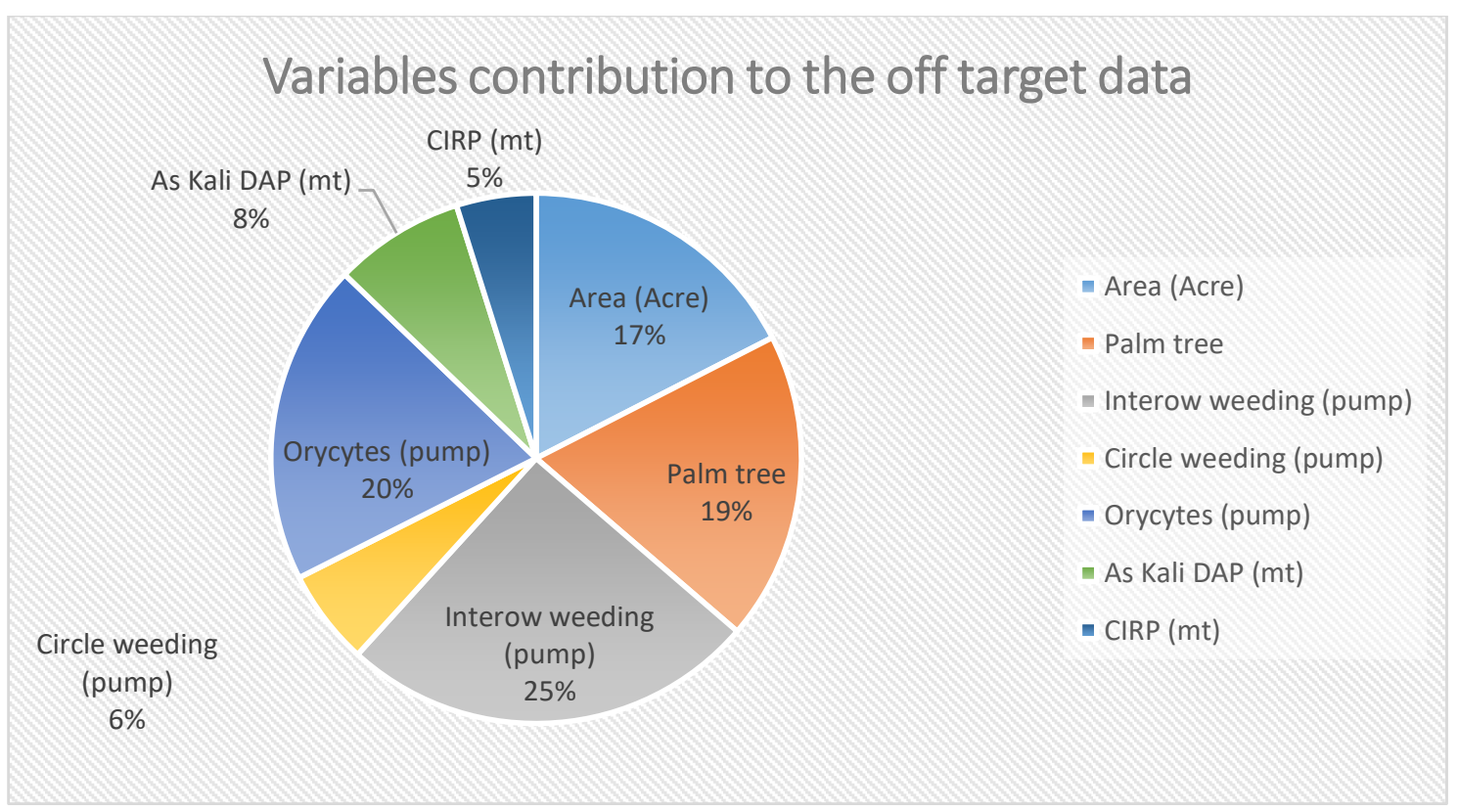

Figure 6 Variables contribution to the off-target data.

\section{CONCLUSIONS}

This research has successfully construct a healthy group using historical data by collecting the data from activity center of replanting field. There is a total of 15 block in the plantation that were selected as the unique identifier. The parameters that being collected are area of each sample block, number of palm trees in each block, interrow weeding maintenance, circle weeding maintenance, orycytes maintenance, As Kali DAP manuring, CIRP maintenance and harvesting of fresh fruit bunch. The target participant is the harvesting of fresh fruit bunch. This research also successfully measures the degree of abnormality using MTS. The abnormality successfully constructed using Kanri Distance Calculator. There are 5 sample blocks; PR16 B3, PR17 C5, PR15 A5, PR16 B5 and PR17 C4 that belong in the abnormality. PR16 B3 and PR17 C5 needs to be evaluate carefully because their Mahalanobis distance is the highest and eventually affected the overall oil palm production. Finally, this work successfully diagnoses the parameters that influence the system. Interrow weeding is the parameters that most influence the system. Among all the parameters, interrow weeding contribute $25 \%$ to the Mahalanobis distance of unhealthy group. It can be concluded here is this parameter need to be diagnosed by increasing the dosage of interrow weeding so that the harvesting output performance can be improve.

\section{ACKNOWLEDGEMENT}

The author would like to be obliged to University Malaysia Pahang for providing financial assistance under RDU1803102.

\section{REFERENCES}

[1] Din, A. K. (2017). Dr. Ahmad Kushairi Din Malaysian Oil Palm Industry Performance 2016 and Prospects for 2017.

[2] Mota-Gutiérrez, C. G., Reséndiz-Flores, E. O., \& Reyes-Carlos, Y. I. (2018). Mahalanobis-Taguchi system: state of the art. International Journal of Quality and Reliability Management, 35(3), 596613.

[3] Chen, J., Cheng, L., Yu, H., \& Hu, S. (2018). Rolling bearing fault diagnosis and health assessment using EEMD and the adjustment Mahalanobis-Taguchi system. International Journal of Systems Science, 49(1), 147-159.

[4] Reséndiz, E., Moncayo-Martínez, L. A., \& Solís, G. (2013). Binary ant colony optimization applied to variable screening in the Mahalanobis-Taguchi System. Expert Systems with Applications, 40(2), 634-637. 
[5] Mota-Gutiérrez, C. G., Reséndiz-Flores, E. O., \& Reyes-Carlos, Y. I. (2018). Mahalanobis-Taguchi system: state of the art. International Journal of Quality and Reliability Management, 35(3), 596613.

[6] Liparas, D., Angelis, L., \& Feldt, R. (2012). Applying the Mahalanobis-Taguchi strategy for software defect diagnosis. Automated Software Engineering, 19(2), 141-165.

[7] Jin, X., \& Chow, T. W. S. (2013). Anomaly detection of cooling fan and fault classification of induction motor using Mahalanobis-Taguchi system. Expert Systems with Applications, 40(15), 5787-5795.

[8] Hadighi, S. A., Sahebjamnia, N., Mahdavi, I., Asadollahpour, H., \& Shafieian, H. (2013). Mahalanobis-Taguchi System-based criteria selection for strategy formulation: a case in a training institution. Journal of Industrial Engineering International, 9(1), 1-8.

[9] John, B. (2014). Application of Mahalanobis-Taguchi system and design of experiments to reduce the field failures of splined shafts. International Journal of Quality and Reliability Management, 31(6), 681-697.

[10] El-Banna, M. (2017). Modified Mahalanobis Taguchi System for Imbalance Data Classification. Computational Intelligence and Neuroscience, 2017.

[11] Reséndiz, E., \& Rull-Flores, C. A. (2013). Mahalanobis-Taguchi system applied to variable selection in automotive pedals components using Gompertz binary particle swarm optimization. Expert Systems with Applications, 40(7), 2361-2365. 